by considerable attention to elementary conformal mappings. Good in itself, this study prepares the reader for the two-fold aspect, topological and analytical, of Cauchy's theorem, where Artin's ideas make for comparative simplicity. In effect, Prof. Ahlfors cuts the topology of the subject to the minimum and then gives that minimum with the utmost clarity and precision. The calculus of residues receives meagre treatment: it is off the main line, and Lindelöf's own beautiful monograph is easy to obtain. Elliptic functions are excluded, Prof. Ahlfors expressly referring the reader to Copson's classical book on the complex variable. Space thus saved is given to two chapters, one on the recent work referred to above, and the other to the theory of multiply-valued functions, which is clear enough as an introduction but scarcely goes far enough to be either satisfying or provocative; twenty pages more here might have explored the main foundations of algebraic functions. In all, this is a clear, authoritative, up-to-date treatise, thoroughly suitable for the undergraduate beginning to specialize in function theory.

\section{OCCURRENCE OF PETROLEUM IN THE EASTERN HEMISPHERE}

The World's Oilfields

The Eastern Hemisphere. Editor : Prof. V. C. Illing. (The Science of Petroleum, Vol. 6, Part 1.) Pp. viii +174 . (London, New York and Toronto: Oxford University Press, 1953.) 52s. 6d. net.

I IKE the previous addenda to "The Science of 1 Petroleum", this is a very fine book. Written by a selection of contributors, each vessel in a particular terrain, it deals with the subject as a whole and forms a work of reference limited only by the knowledge available at the time of writing. Therein, as is natural, may lie a fow limitations. So far as petroleum at present is concerned, the "Eastern Hemisphere" is chiefly Europe and the Middle East. In the case of Europe, information that is, or has been, readily accessible (such as that regarding Germany, Poland and Roumania) is already fairly well known; what has not been accessible and was mostly unknown when volume 1 of "The Science of Petroleum" was published in 1938 (for example, developments in Austria and Hungary) includes the more important new fields largely developed subsequent to the outbreak of the Second World War and still behind the Iron Curtain. The result is that in these sections, where knowledge of production is sparse, the treatment seems rather heavily weighted on the side of general geology. This is so, to some extent, even with the important fields of the Middle East, on which however, by reason of their broader outlook, the articles by Lees are refreshing to read. Although oilfields are sub-surface affairs, it is natural that exploration, their discovery, delimitation, development and handling of production should be of the widest interest. One is consequently apt to miss the treatment in Vol. 1, wherein a single part of discussion of individual oilfields was in proportion to some five parts of the general aspects of production concerned with geophysics, siting, drilling, fieldengineering and transportation.

The present volume is therefore of greatest importance to students and workers in the field of petroleum geology. The pattern of treatment in the sub-sections is to follow a short introduction with details of the stratigraphy and tectonics of the area concerned. The oil-source rocks are then discussed separately. Good use is made throughout of effective tabulation, and maps and diagrams are excellent. The sections dealing with the Far East and Australasia, and with Africa, contain articles by fourteen separate authors. They vary in length; but the majority, though short, succeed in giving general outlines of the oil geology of the extensive but not very productive areas concerned. In this way, the implications of subsequently acquired information or diseovery afterwards made can readily be fitted in.

Prof. Illing and his contributors are to be congratulated on producing a volume which will be of permanent value in the study of the occurrence of petroleum.

S. J. M. AULD

\section{MARGINAL LAND IN BRITAIN}

Marginal Land in Britain

By Prof. W. Ellison. Pp. $224+16$ plates. (London : Geoffrey Bles, 1953.) 25s. net.

DUBLIC attention has been directed repeatedly in Great Britain to the possibilities of marginal land improvement during the past ten years or so, and the absence of any comprehensive book on the subject has meant a substantial gap in agricultural literature. This gap is now filled very adequately by Prof. W. Ellison's book. It cannot be easy to write a book which will be read with interest and profit by both the farmer, on one hand, and the scientist and administrator on the other. Prof. Ellison, we know, is an enthusiast for reclamation and rehabilitation of the land and farmsteads of British uplands; but unlike so many agricultural enthusiasts before him, he has been content to give an ungarnished factual account of the nature and extent of the problem, drawing on his own and other people's practical experience to show with facts and figures how production can be increased from this type of land, and at what cost. It is a great merit of the book that the agricultural problem of marginal land in the uplands is always kept in perspective, both in relation to its alternative use for forestry and water-gathering grounds, and to the needs of the lowland farmer upon whom the upland farmer so largely depends.

The book begins with a historical introduction and goes on to describe the findings of the various committees which have considered the problem in recent years. The different types of marginal land in Great Britain are defined and delineated on folding maps. There follow valuable sections on the methods of improvement appropriate to these different types and on the utilization of the resulting increase in production of crops and grass. The author's discussion of the extent to which, in the uplands, rehabilitation of the farm-houses, buildings, roads and services must accompany improvement to the land is based on actual surveys, which emphasize the high capital costs involved.

If there is an omission from this otherwise wellbalanced book, it is perhaps the relatively slight reference to the personel factors in this problemthe labour force (family and hired); the landlord; and, most important, the abilities and shortcomings of the farmer himself. 